\title{
The Free Rhythm in National Vocal Performance
}

\author{
Shuyue Ding \\ School of Media \\ Mianyang Teachers' College \\ Mianyang, China 621000
}

\begin{abstract}
China is an ancient civilization with a long history, a vast area and a large population. In its long history, the people of all ethnic groups left rich precious cultural heritage and splendid spiritual wealth. The Chinese national vocal art is one of them. The free rhythm is very common in our country's national vocal performances. It is conducive to the improvisation and freedom of singing. This article discusses the free rhythm in national vocal performances.
\end{abstract}

Keywords—national vocals; free rhythm; origin

\section{INTRODUCTION}

China's national vocal art has a long history of development. The generalized national vocals include traditional opera singing, quyi rap and folk song singing. With China's strengthening the protection of national culture, the types of national vocal performances have also been attached great importance. The free rhythm in national vocals has enriched the national vocal performances, and its role should not be ignored.

\section{THE ORIGIN AND DEVELOPMENT OF FREE RHYTHM}

As early as in ancient times, people clapping to sing, this is the earliest manifestation of the free rhythm, which is called the "free beat". In ancient times, there was no substantial demand and constraints for this free beat. People simply clapped their hands with the singer's tone and the scene in which he sang songs. In ancient times, rhythms and beats had not yet been distinguished. They were collectively referred to as rhythms. This unconstrained beat is the earliest form of the free rhythm.

With the continuous development of the society, in the Tang Dynasty, a prosperous period for music had come. The development of music reached its peak in the Tang Dynasty and it had also contributed to the development of the world culture. In the Tang Dynasty, poetry was very popular and people gradually found new beat methods from the poems. The new beat came from the expression of the rhythm of the poetry, which was knocking once on a board after each sentence had been sung, indicating the end of the last sentence and the beginning of the next sentence. This beat was called "rhythmical beat" in the Tang Dynasty.

The free rhythm is very common in China's national vocals. Most of the ancient Chinese national vocals were taught by the teacher to the student through the teacher's mouth. Because different person had different understanding of the same vocal, at the same time, the ancient vocals had no fixed beats or scores, the same vocal therefore had been presented with different speeds and lengths after being studied by different people. This had created a lot of space for free rhythm.

When in the Ming Dynasty, China's national vocals began to have fixed tempos. In the Ming Dynasty, it was stipulated that the board should be knocked on only after two beats or four beats, but China's quantitative beat has not been strictly quantity limited. The development of Chinese national vocals has undergone three processes: natural rhythm, rhythmical beat, and prescribed beat. With the continuous development of music, the rhythm has become orderly and normative from being free, and the new rhythm is continuously making progress on the basis of the old rhythm. The development of free rhythm has created a space for the vocals. By standardizing and organizing the free rhythm, complete works are formed.

The free rhythm not only plays an important role in the development of Chinese vocal music, but also plays an important role in the development of music in the world. For example, in the music of Jomon Period, Yayoi Period and Ancient Tomb Age of Japan, there was the free rhythm, and the famous Japanese musician Koizumi Wenfu also made a special exposition on the free rhythm in his works. With the continuous development of music, free rhythm has also been well presented in China's national vocals. Many music works have the right to deal with free rhythms, and free rhythm has also been widely used in contemporary national vocal performances.

\section{THE MANIFESTATION OF FREE RHYTHM IN NATIONAL VOCALS}

China is a multi-ethnic country. The different languages of different nationalities make vocals show different styles. Different linguistic features of different nationalities make vocal music works having different styles and colors. For example, the Han language belongs to the Sino-Tibetan language family and is a monosyllabic language system with a variety of tones. Monosyllable means that one Chinese character only has one syllable. Each syllable consists of three elements: consonant, vowel, and tone. National vocals are influenced by many factors such as the voice, style, context, force, syllables, and the relationship between morphemes, vocabulary, and the internal system of lexical meanings, resulting in different styles and colors of vocals. China's national vocal music has a long history of development and 
has received a great deal of praise since ancient times. Today, there has been the special education of national vocals. There are also many modern national vocal singers such as Song Zuying and Peng Liyuan, which has made our country's national vocal music more splendid and brilliant. The use of free rhythm in the national vocal music is also very extensive. The free rhythms that appear in local folk songs in our country, the free rhythm in operas, and the free rhythm in the created songs all play a role that cannot be ignored in these works. The free rhythm has a very profound embodiment in local folk songs in Yunnan. Yunnan is a multi-ethnic province with many ethnic minorities such as Yi, Bai, Dai, Hani, Zhuang, Miao, and so on, so Yunnan has a variety of ethnic music, and traditional operas and rap music like Bai dramas, Zhuang dramas, Dai dramas, dulcimer, and Daben traditional operas. In many ethnic groups in Yunnan, when children are still at the stage of learning to speak, they begin to follow adults singing. The free rhythm is made full play of its role in Yunnan's national vocal music. For example, in the Han nationality in Yunnan, the most distinctive form of singing folk songs is that the two singers who are going to sing antiphonal songs must maintain a certain distance. Before singing the formal content of the song, they must first sing a long previous aria. However, there are different styles of national vocals in different parts of Yunnan. Most of the folk songs have no fixed lyrics, and are improvised to sing. They have a great impact in the country. Songs such as "Shuashan Tune" and "Driving the Horse Tune" have already had different styles after being interpreted by ethnic groups in Yunnan according to the free rhythm and their own national customs. There are the Yi people's "Shuashan Tune", the Bai people's "Shuashan Tune" and the Dai people's "Shuashan Tune".

The free rhythm in the opera gives the performer more space to express his feelings. We all know that opera is a western stage performance art. Simply speaking, it is a drama that narrates and expresses a story mainly or completely with singing and music. The opera is a concrete expression of the story, and actors present the story to the audience through their performances. The free rhythm in the opera can make the singer's emotion be expressed more naturally, and the free rhythm makes the opera performance livelier.

Free rhythm is more common in composition songs. In the modern era, with the rapid development of culture and music, songs have become indispensable in people's lives. For an outstanding music work that we have heard, it will become another excellent piece of music after undergoing an adaptation of free rhythm. The "South of the Southern Mountain", "The Most Beautiful Sun" and "Ordinary Path" that we often listen to have all undergone the adaptation of free rhythm, and have made use of the improvisation and creativity of the free rhythm to become new outstanding works.

\section{THE SignifiCANCE OF FREE RHYTHM IN VOCAL PERFORMANCES}

\section{A. Helping to Improve the Freedom of Performances}

In modern national vocal music, each piece has a fixed beat. However, if we carefully listen to the singer's singing, we will find that her singing is not exactly in line with the existing rhythm of the work. For the same music work, it will have different free beats when being sung by the singer in different scenes or different environments. If we repeatedly listen to the same song, we will be jaded. Listening to the same vocal work repeatedly will be the same. Therefore, singers add different emotional factors and different singing tones to vocal performances to make the free rhythm well integrated with the vocal works. Each singing is the second creation of the work by the singer. With the addition of the free rhythm, vocal works become living, attractive and charming.

\section{B. Helping to Shape the Style of the Work}

The musical style refers to the personalized combination of a variety of musical elements - tune, rhythm, timbre, strength, harmony, texture, musical form, etc., but mainly refers to the tune. The personalized combination of these elements can produce a significant or unique sound. With the advancement of the times and the research and exploration of national vocal arts, national vocal music shows a trend of various styles developing together. In national vocal music, the style of a work is mainly reflected in two aspects: one is the style of the work itself, and the other is the style of the performer, specifically including the features and styles expressed in the second creation.

China has a vast territory and 55 ethnic minorities have their own characteristics. There are Uygur folk song "Raise your red veil", Daur folk songs, Miao folk song "Singing the beautiful hometown", Hui folk song "Red flowers bloom and the mountain becomes red", Highmesa folk song "Pestle", Bai folk song "The love song under the moon", etc. Uygur traditional folk songs include love songs, labor songs, historical songs, and lifestyle songs. According to their contents, the Miao folk songs can be divided into love songs, wine songs, bitter songs, anti-songs, funeral songs, labor songs, political songs, nursery rhymes, and riddles. These types of songs have different tunes and styles. The free rhythm has participated in the formation of the different styles. The development of free rhythm has promoted the formation of different national vocal styles.

For each national vocal music work, the singers must deeply root in the fertile soil of their own country and nation, so that the singer's singing can have a strong national style, national temperament, and ethnic characteristics. In the development process of national vocal music in our country, the participation of free rhythms and the use of western techniques for vocal music creation have made our country's national vocal music more and more mature and gradually going to the world. Adding free rhythm to the music is an important way of creating vocal music works. Free rhythm has played an important role in shaping national vocal music styles. For example, the long previous aria of Yunnan national vocal music can make the distance between singers closer and attract people's attention. At the same time, it can also demonstrate the appeal of Yunnan ethnic vocal music. The formation of the singer's artistic style is inseparable from the singer's personal pursuit and exploration of free rhythm. At the same time, the formation of style has a close relationship with the development of the society. From the perspective of the development of the times, the aesthetic needs at a specific 
historical stage have an important influence on the formation of the singer's artistic style. Every singer has a unique artistic style, such as Song Zuying with a delicate style and Peng Liyuan with a deep and decent style. The singers' use of free rhythm makes each of them segment songs differently. For example, when Li Shuangjiang sings "When Will Sophora Flowers Bloom", it is passionate; when the song is sung by $\mathrm{Wu}$ Bixia, it is euphemistic and lyric. The addition of free rhythm makes this song appear in different styles when sung by different singers. People in different social strata and different living environments have different perceptions about works. The work with multiple styles can be more attractive and correspondingly have more influence on the society.

\section{Helping to Express the Feelings}

Music is an important way for people to express their feelings. Vocal music is as well. National vocal music expresses the feelings of a nation. People can feel different moods by listening to the music. Happiness, sadness, and calmness can all be expressed through music. For national vocal performers, only after they understand the meanings of works themselves, plus the exertion of their own emotions, can they complete perfect performances and resonate with the audience. For a performer, a performance without personal emotions is a soulless performance; for a work, it expresses emotions through the fixed score and beat. The presentation of different styles of the same work needs the participation of free rhythms. The free rhythms in the works make the works vital. The free rhythm is integrated into the national vocal performances, which is conducive to the expression of the works' emotions and the performers' emotions. Rhythm is the connecting point for music, which can stimulate people's external senses, and can also inspire people's inner emotions. At the same time, the combination of rhythm and the content of the work make the audience penetrate into the work and integrate themselves into the context described by the work, arousing the audience's emotional cognition, and thus making the performance enter a higher realm.

\section{THE DISTRIBUTION OF FREE RHYTHMS IN VOCAL MUSIC}

The distribution of free rhythms in vocal music has many characteristics. Some free rhythms are in the introductory part or at the beginning of vocal music works, some in the middle, some in the refrain part, and some in the end. There are usually two parts of free rhythm in vocal music: the free rhythm in the introductory part and the free rhythm in the formal part. The introductory part is usually the foundation and foreshadowing for the free aria part. In our country's traditional national vocal music, the free rhythm is well used. One of the 25 best folk songs in the world--the "Dragon Boat Tune" was originally called "Grow Melon Tune" and was originally a folk song that was often sung by the people in Enshi Tujia and Miao Autonomous Prefecture in Hubei Province when they were boating during the festivals. Part of the song is: "Lunar January is the New Year (Na yi yo wei), the young girls are coming to celebrate the New Year (Na wei)! Jin na yin er suo yin na yin er suo! The sparrow is chirping (Wa yi ya wei zi yo,na ge yi ya wei zi yo)!" The "Na yi yo wei,na wei,jin na yin er suo yin na yin er suo, wa yi ya wei zi yo, na ge yi ya wei zi yo" in the four sentences are the use of free rhythm. The free rhythm makes "Dragon Boat Tune" have a cheerful, lively atmosphere and enhances the emotional property of the music. Another example is the folk song in Hunan area and the representative song of Chinese intangible cultural heritage Sangzhi folk songs

"Set up a lamp stand under the Masang tree" .Part of the song is:"Set up a lamp stand under the Masang tree(yo he), writing a letter(ye) to me (yo), you went to the army while I(ye) was staying at home (ya), I can't see you in 3-5 years (yo), you will fall in love with other(ye) woman (yo)." The "yo he, ye, yo" in these sentences are also the exertion of free rhythm. These free-rhythm additions have made the Sangzhi folk song "Set up a lamp stand under the Masang tree" pathetic and be sung for a long time.

\section{THE Position OF FREE RHYTHM IN THE NATIONAL VOCAL MUSIC}

National vocal music is a precious asset left during China's long history. The development of the nation and the progress of the times are also constantly promoting the innovation and development of national vocal music. Creating the singing art with Chinese characteristics is the goal of developing national vocal music in China. With the efforts of Chinese people, the national vocal music in our country has been fully developed in the new era and has entered the most prosperous stage. The free rhythm has played an important role in the national vocal music of our country from ancient times to the present. The vocal music in which there is no free rhythm has no soul. Well using the free rhythm is a necessary skill for national vocal performers. Only when the performers deeply understand the importance of free rhythm and apply it to their performances can they achieve perfect performances. The free rhythm not only enables performers to recreate the works, but also makes the performance fully express the inner feelings of the performers and the works, so that the audience can have emotional resonance and integrate them into the national vocal performance. This is also the ultimate goal that national vocal performance is pursuing. In the process of learning national vocal music, we must fully understand and try to use the free rhythm to present the different wonderful contents of different works, and integrate free rhythm into each piece of work and into our hearts, making it become part of the performance. The free rhythm has an important irreplaceable significance for the national vocal music performance in China.

\section{CONCLUSION}

The free rhythm in national vocal performances is indispensable, and free rhythm has a great impact on the recreation of works. Works without free rhythm are lifeless. The free rhythms in national vocal performances enable the performers to fully express their emotions and lead the audience to enter the works. The free rhythm makes the national vocal performance more complete and more contagious. 


\section{REFERENCES}

[1] Zhang Yumeng. Free rhythm and the formation and expression of national vocal performances [J]. Literary life, literary theory, 2015, (1): pp.86-87. 张屿梦.自由节奏与民族声乐表演的塑造与表达 $[\mathrm{J}]$. 文艺生 活·文艺理论,2015,(1):86-87.

[2] Liu Haiyan. Interpretation of the theoretical value of traditional Chinese vocal singing theory in contemporary national vocal performance teaching [J]. Silk Road Vision, 2017, (27): pp.106-107. 刘海燕.中国传 统声乐唱论在当代民族声乐表演教学中的理论价值解读 [J]. 丝路视 野,2017,(27):106-107.

[3] Tang Qiufeng. A brief discussion on the status quo and artistic research of national vocal performances[J]. Northern Music, 2016, (4): p.21. 唐 秋风. 浅谈民族声乐表演的发展现状以及艺术研究 [J]. 北方音 乐,2016,(4):21. 